\title{
EFFECT OF CHEMICAL TREATMENT \\ WITH OXIDANTS ON THE MECHANICAL PROPERTIES OF LUFFA SPONGE/UNSATURATED POLYESTER COMPOSITES
}

\author{
NOURI LAIB, AZZEDINE BENYAHIA, ALI REDJEM and NADIR DEGHFEL \\ Laboratoire Ville, Société, Environnement et Développement Durable, Université de M'sila, Algeria \\ \orresponding author: A. Benyahia, azzedine.benyahia@univ-msila.dz
}

Received November 21, 2020

This study investigates a synergistic treatment comprising alkali, permanganate, dichromate, silane and bleaching pretreatment on Luffa sponge (LF) fibers intended to be used as reinforcement in an unsaturated polyester (UP) matrix to improve the mechanical properties of Luffa sponge fibers reinforced unsaturated polyester composites. Treatment effects by $\mathrm{NaOH}(5 \mathrm{wt} \%), \mathrm{K}_{2} \mathrm{Cr}_{2} \mathrm{O}_{7}(0.2 \mathrm{wt} \%), \mathrm{KMnO}_{4}(0.0125 \mathrm{wt} \%), \mathrm{NaClO}\left(13^{\circ}\right)$ and silane $(0.5 \mathrm{wt} \%)$ on the performance of the prepared composites were evaluated by Fourier transform infrared spectroscopy (FTIR), X-ray diffraction (XRD), SEM and mechanical tests (flexural strength and modulus). The results of the analyses indicated that composites reinforced with treated fibers have higher flexural strength than composites reinforced with untreated fibers.

Keywords: Luffa fiber, composite, alkali treatment, flexural strength

\section{INTRODUCTION}

Natural fibers are an environmentally clean, renewable and biodegradable resource, and more industries are interested in their use. ${ }^{1}$ Moreover, natural fibers are about $50 \%$ lighter than glass and are generally cheaper. It is widely acknowledged that natural fiber composites combine good mechanical properties with low specific mass and provide an alternative material to glass fiberreinforced plastics in certain technical applications. Thus, the study of the mechanical properties of natural fiber composites seems to be of considerable interest. ${ }^{2}$

One natural fiber that has attracted the attention of applied research is Luffa fiber, given its physico-chemical properties. It originates from a subtropical plant of the Cucurbitacea family, which produces a fruit with a fibrous vascular system (Luffa). The fibers are mainly composed of cellulose (54\%), hemicelluloses (20\%) and lignin $(15 \%)$; with sizes ranging from $1.5 \mathrm{~cm}$ to $1.5 \mathrm{~m}$, and an average diameter of $8-10 \mathrm{~cm}$. However, considering that the adhesion strength of natural fiber-reinforced composites is often reduced by moisture absorption, it should be pointed out that the main characteristic of the raw Luffa fibers (without surface treatment) is their capacity to easily absorb moisture, which poses problems in their use as reinforcement material in hybrid composites. ${ }^{3}$

Natural fibers, being hydrophilic in nature, absorb moisture from the environment. This characteristic of natural fibers leads to poor adhesion with the resin matrix, which eventually causes a detachment of the fiber from the matrix. In humid conditions, these composites therefore have very poor mechanical properties. Several researchers have developed composites containing natural and synthetic fillers. Benyahia et al. ${ }^{4}$ studied different chemical treatments, such as mercerization, permanganate, acetylating and dichromate treatments, which were used to modulate the mechanical properties of composites. According to the tensile and flexural tests, the treated composites showed better mechanical performance, compared to their untreated counterparts. Asumani et al. and Islam et $a .^{5-7}$ reported that alkali/silane-treated kenaf fiber composites have better mechanical properties than composites treated with alkali or silane alone. Patel et al. ${ }^{8}$ studied the fabrication and the physical and mechanical properties, as well as the three-body abrasive wear and water 
absorption behavior of Luffa fibre reinforced polyester composites, with and without addition of microfillers of $\mathrm{Al}_{2} \mathrm{O}_{3}, \mathrm{CaCO}_{3}$ and $\mathrm{TiO}_{2}$. It was found that there is an improvement in the physical and mechanical properties of the fiber-based polyester composites with added microfillers. Tanobe et al. ${ }^{9}$ performed two treatments on Luffa fibers, the first treatment with $2 \%(w / w) \mathrm{NaOH}$ for different time periods of 10,60 and 90 minutes. The second treatment was in aqueous solutions of methacrylamide of different concentrations $(1,2$ or $3 \%)$ for different times (60, 120 and 180 minutes). They found that there is an influence on the mechanical and other properties, such as the water absorption characteristics. Dhanola et al. ${ }^{10}$ observed that adding natural fillers, such as ground nut shell, rice husk, and wood powder, to Luffa-reinforced polyester composites led to an improvement in the physical and mechanical properties of the composites, in the following descending order: ground nut shell, rice husk, and wood powder. Boynard et al. ${ }^{11}$ studied the flexural properties of Luffa fiber reinforced polyester composites. They noticed that the flexural modulus increased by $14 \%$ after the alkali treatment of the fibers.

This study aims to evaluate the mechanical properties of Luffa as a reinforcing material for unsaturated polyester composites. The Luffa fibers were subjected to treatment with $5 \mathrm{wt} \%$ $\mathrm{NaOH}, 0.2 \mathrm{wt} \%$ potassium bichromate, 0.0125 wt $\%$ potassium permanganate, bleach water $\left(13^{\circ}\right)$, and $0.5 \mathrm{wt} \%$ silane coupling agent (3aminopropyltriethoxysilan). The chemical treatment reduced the hydrophilicity of the Luffa fibers, thus improving the bond between the matrix and the fiber, reducing the moisture absorption.

\section{EXPERIMENTAL}

\section{Matrix components}

Both unsaturated polyester resin and hardener (SIRESTER FSN 0850/AMT/E) were supplied by SIR Industriale, Italy. The details of the chemical characteristics of the unsaturated polyester resin and the hardener used for the present investigation are given in Table 1.

Table 1

Raw materials and their physical characterisitics

\begin{tabular}{|c|c|c|c|}
\hline Unsaturated polyester & Characteristics & $\begin{array}{l}\text { Methyl ethyl } \\
\text { ketone peroxide }\end{array}$ & Characteristics \\
\hline Specific mass of liquid at $25^{\circ} \mathrm{C}$ & $1.06 \mathrm{~g} / \mathrm{cm}^{3}$ & Aspect & Colorless liquid \\
\hline Specific mass of solid at $25^{\circ} \mathrm{C}$ & $1.16 \mathrm{~g} / \mathrm{cm}^{3}$ & Active oxygen & Approx. $8.8-9.4 \%(\mathrm{w} / \mathrm{w})$ \\
\hline Viscosity at $25^{\circ} \mathrm{C}$ & $400 \mathrm{mPa} \cdot \mathrm{s}^{-1}$ & Density at $20^{\circ} \mathrm{C}$ & Approx. $1.1{\mathrm{~g} . \mathrm{cm}^{-3}}^{-3}$ \\
\hline Gel time & $7 \mathrm{~min}$ & Viscosity & Approx. $30 \mathrm{mPa} . \mathrm{s}$ \\
\hline Peak gel time & $15 \mathrm{~min}$ & Desensitizing agent & Phtalate \\
\hline Peak temperature & $170^{\circ} \mathrm{C}$ & Miscibility & $\begin{array}{l}\text { Immiscible with water, } \\
\text { phthalate soluble }\end{array}$ \\
\hline Glass transition & $130^{\circ} \mathrm{C}$ & $\begin{array}{l}\text { Recommended } \\
\text { storage temperature }\end{array}$ & Below $30^{\circ} \mathrm{C}$ \\
\hline Styrene content & $41 \mathrm{wt} \%$ & Stability at $25^{\circ} \mathrm{C}$ & 12 months \\
\hline
\end{tabular}

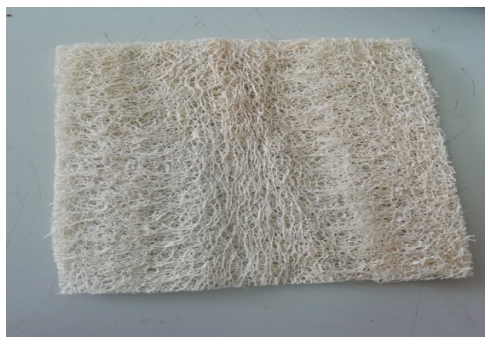

Figure 1: A rectangular portion of Luffa sponge

Unsaturated polyester and styrene were mixed in the ratio of 100:25 parts by weight respectively. Subsequently, $1 \mathrm{wt} \%$ methyl ethyl ketone peroxide and
1 wt $\%$ cobalt naphthenate were added and mixed thoroughly. 


\section{Chemical treatments of Luffa sponge}

The Luffa sponge gourds were obtained from local producers in M'sila, Algeria. Figure 1 shows the aspect of the sponge. Their overall length was about $1 \mathrm{~m}$. They were first cut into lengths of $140 \mathrm{~mm}$ and then split longitudinally into two. The Luffa fibers were subjected to several surface treatments to improve the interfacial adhesion between the Luffa fibers and the unsaturated polyester matrix.

\section{Alkali treatment}

The alkaline solution used for treatment of the fibers was prepared from sodium hydroxide, supplied by Sigma-Aldrich (degree of purity $98 \%$, density 2.3 g.cm ${ }^{-3}$, melting point $\left.318^{\circ} \mathrm{C}\right)$.

The Luffa sponge (Luffa cylindrica) was deposited in a glass tray. A $5 \mathrm{wt} \% \mathrm{NaOH}$ solution was added into the tray and the sponge was left to soak in the solution for $4 \mathrm{~h}$. The Luffa sponge fibers were then washed thoroughly with water to remove excess $\mathrm{NaOH}$ that stuck to the fibers. The final washing was carried out with distilled water and the fibers were dried in a hot air oven at $80{ }^{\circ} \mathrm{C}$ for $5 \mathrm{~h}$.

\section{Bichromate treatment}

The potassium bichromate used in this treatment was supplied by Biochem Chemopharma, degree of purity $99.8 \%$, melting point $398^{\circ} \mathrm{C}$.
The Luffa sponge was soaked in $0.2 \%$ $\mathrm{K}_{2} \mathrm{Cr}_{2} \mathrm{O}_{7} /$ acetone for $5 \mathrm{~min}$. The fibers were then removed, washed several times with distilled water and dried in an oven at $80{ }^{\circ} \mathrm{C}$ for $5 \mathrm{~h}$.

\section{Permanganate treatment}

Potassium permanganate (CE-EMB 45053) with the degree of purity of $99 \%$, density $2.7 \mathrm{~g} . \mathrm{cm}^{-3}$, melting point $240{ }^{\circ} \mathrm{C}$, was used.

The sponge gourd sample was placed in a 0.0125 wt $\%$ solution of $\mathrm{KMnO}_{4}$. A quantity of $2 \mathrm{~mL}$ of acetic acid $(0.1 \mathrm{~N})$ was added and the Luffa sponge was left to soak for $3 \mathrm{~min}$, then it was washed with distilled water $(1 / 2)$ and dried in an oven at $80^{\circ} \mathrm{C}$ for $5 \mathrm{~h}$.

\section{Bleach water treatment}

The sodium hypochlorite $(\mathrm{NaClO})$ used for the treatment of the fibers was "Bref Javel", supplied by Henkel, Algeria, with a degree of purity of $99.99 \%$.

The Luffa sponge sample was placed in $2 \mathrm{~L}$ of concentrated bleach solution $\left(13^{\circ}\right)$, with $2 \mathrm{~mL}$ of sulfuric acid $(0.1 \mathrm{~N})$ for $5 \mathrm{~min}$. Then, the Luffa sponge was washed with distilled water $(1 / 2)$ and dried in an oven at $80{ }^{\circ} \mathrm{C}$ for $5 \mathrm{~h}$.

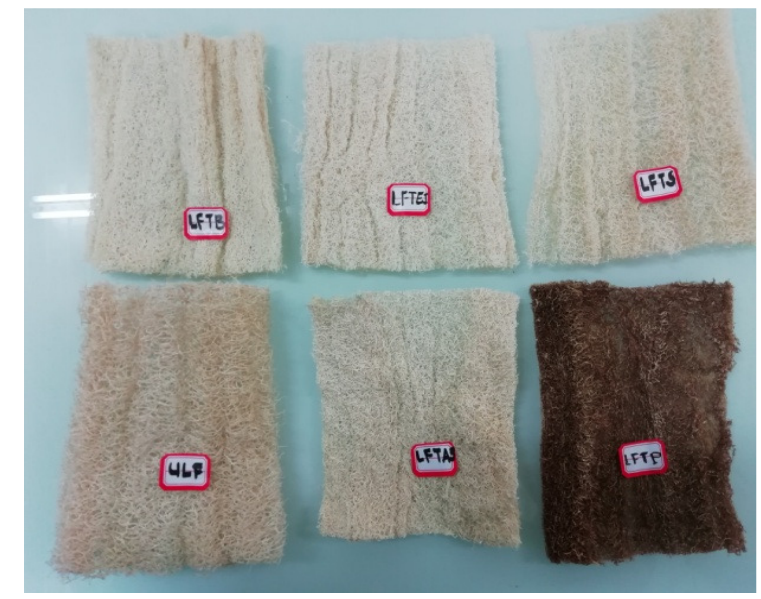

Figure 2: Samples of untreated and treated Luffa sponge

\section{Silane treatment}

The silane (3-aminopropyltriethoxysilane) used for surface modification of the fiber was supplied by Fluka Chemika (chemical formula: $\mathrm{C}_{9} \mathrm{H}_{23} \mathrm{NO}_{3} \mathrm{Si}$, degree of purity $96 \%$, density 0.949 ).

The Luffa sponge fibers were treated with an aqueous solution of silane to produce the composite. An amount of $0.5 \mathrm{wt} \%$ silane, based on the fibers, was dissolved in distilled water and stirred for $1 \mathrm{~h}$ for hydrolysis. The ratio of fibers to silane in aqueous solution was maintained at 1:10. The aqueous solution of silane was acidified to $\mathrm{pH} 3.5-4$ with acetic acid. The fibers were immersed in the solution and left for $24 \mathrm{~h}$ at room temperature. The fibers were then rinsed in distilled water and dried at $80{ }^{\circ} \mathrm{C}$ for $24 \mathrm{~h}^{12}$ Figure 2 shows the different treatments on the test sample (Luffa sponge).

\section{Fabrication of composites}

The preparation of unsaturated polyester matrix composites with a $20 \mathrm{wt} \%$ fraction of Luffa sponge fibers was carried out by the hand lay-up technique. 
NOURI LAIB et al.

Previously pressed fiber sheets were impregnated into the mixture of unsaturated polyester resin components (at a ratio of 100:20). Subsequently, the Luffa sponge sheets were placed into a metal mold $(150 \times 200 \times 3$ $\mathrm{mm}^{3}$ ) to obtain an isotropic structure. A $5 \mathrm{MPa}$ pressure was then applied using a hydraulic press. The composites were cured at room temperature.

\section{Characterization \\ Water sorption test}

The hygroscopic character of the fibers was determined by introducing 100-180 mg of fibers into a container. Water absorption was measured at $2 \mathrm{~h}$ intervals until the weight was stabilized. The percentage of water sorption in the samples was calculated based on Equation (1):

$$
\frac{\Delta W}{W_{i}}=\frac{W_{f}-W_{i}}{W_{i}} \times 100
$$

where $\Delta W=$ water sorption $(\%) ; W_{f}=$ sample weight after immersion in water; $W_{i}=$ sample weight before immersion in water.

\section{Fourier transform infrared spectroscopy (FTIR)}

Both untreated and treated Luffa sponges were subjected to FTIR analysis. Powder samples with a particle size less than 200 mesh were dispersed in potassium bromide $(\mathrm{KBr})$ in a weight ratio of $1: 100$. The spectra were recorded by a Vertex $70 \mathrm{v}$ (BRUKER, Karlsruhe, Germany), obtained in the transmission mode over a scanning range from 4000 $\mathrm{cm}^{-1}$ to $400 \mathrm{~cm}^{-1}$, with a resolution of $4 \mathrm{~cm}^{-1}$. Each group was measured three times to avoid any error.

\section{$X$-ray diffraction analysis (XRD)}

The crystallinity of Luffa sponge fibers was evaluated by X-ray diffractometry using an X'Pert High Score diffractometer (X'Pert Pro PW3209, PANalytical, France). Equatorial diffraction patterns (2 h) were recorded from 10 to $60^{\circ}$, using $\mathrm{Cu}-\mathrm{Ka}$ radiation at $40 \mathrm{KV}$ and $20 \mathrm{~mA}$. X-ray diffraction was used to study the physical structure changes of the fibers in terms of crystallinity index (CI). Segal et al. ${ }^{13}$ developed an empirical method to estimate the degree of crystallinity of native cellulose (Cellulose I). The amount of crystalline Cellulose I in total cellulose can be expressed by Equation (2):

$$
\operatorname{Cr} \%=\frac{I_{002}-I_{a m}}{I_{002}}
$$

where $\mathrm{I}_{002}$ is the intensity of the principal Cellulose I peak at a $2 \theta$ angle around $22.7^{\circ}$, and $\mathrm{I}_{\mathrm{am}}$ is the intensity attributed to amorphous cellulose at a $2 \theta$ angle around $18.9^{\circ}$.

\section{Thermogravimetric analysis}

The TGA was performed on a TA-60WS work station analyser (Shimadzu Corp.; Kyoto, Japan) at a heating rate of $10{ }^{\circ} \mathrm{C} \cdot \mathrm{min}^{-1}$. The samples were examined under nitrogen flow $\left(80 \mathrm{~mL} \cdot \mathrm{min}^{-1}\right)$ over a temperature range from 30 to $900{ }^{\circ} \mathrm{C}$.

\section{Scanning electron microscopy}

A Jeol JSM-7001F scanning electron microscope (SEM), at $20 \mathrm{kV}$ accelerating voltage, was used to study the fracture surface of the composites. The samples were mounted on the stub by carbon tape. Then, the photomicrographs were taken at $20 \mathrm{kV}$ accelerating voltage.

\section{Flexural testing of composites}

Flexural testing of the composite samples was performed using a Universal Testing Machine (YL-25Machine Overview, Germany). The testing was carried out in accordance with ASTM D790. The flexural strength (FS) and flexural modulus (FM) of the composite samples were determined using Equations (3) and (4):

$$
\begin{aligned}
& \text { Flexural Strength }=\frac{3 P L}{2 b t^{2}} \\
& \text { Flexural Modulus }=\frac{P L^{3}}{4 b t^{3} W}
\end{aligned}
$$

where $L$ is the span length of the sample; $P$ is the load applied; $b$ and $t$ are the width and thickness of the sample, respectively; $W$ is the deflection.

Table 2 lists the coding of the different composite samples.

Table 2

Coding of the different composite samples studied

\begin{tabular}{lc}
\hline Composite code & Formulation \\
\hline ULF/UP & Untreated Luffa fiber/unsaturated polyester \\
LFTA5/UP & $5 \%$ Alkali treated Luffa sponge/unsaturated polyester \\
LFTP/UP & Permanganate treated Luffa sponge/unsaturated polyester \\
LFTB/UP & Bichromate treated Luffa sponge/unsaturated polyester \\
LFTEJ/UP & Bleach treated Luffa sponge/unsaturated polyester \\
LFTS/UP & Alkali treated Luffa sponge/unsaturated polyester \\
\hline
\end{tabular}




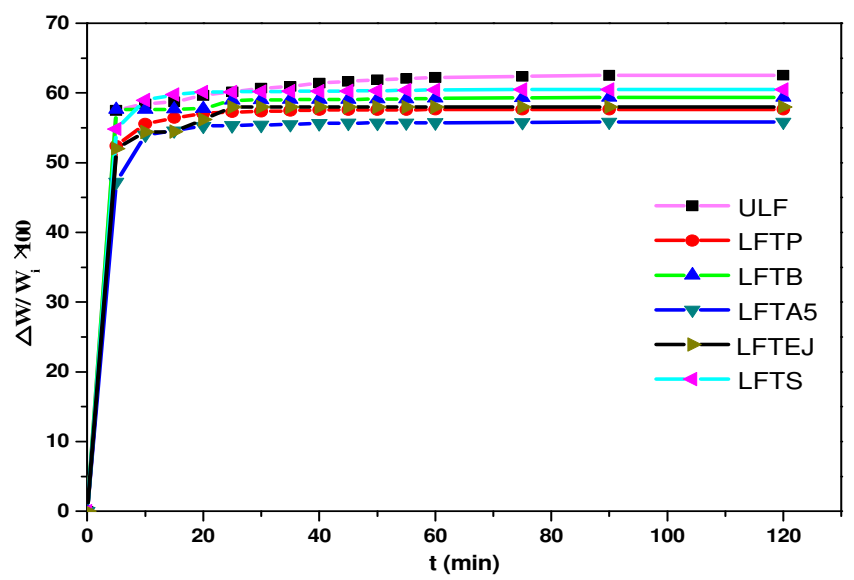

Figure 3: Water absorption as a function of water immersion time of the untreated and treated Luffa sponge samples

\section{RESULTS AND DISCUSSION Water sorption test}

The water absorption behavior of natural composites is largely influenced by many factors, such as the chemical and physical treatments of the natural fibers, the permeability of the fiber, the crystallinity of the host resin etc. According to the results presented in Figure 3, it can be observed that the water sorption rate is significantly higher at the beginning of the test. Then, the values tend to stabilize and become almost constant, which corroborates the results reported by M. Nóbrega et al. ${ }^{14}$

According to de Paula et al., ${ }^{15}$ lignocellulosic materials tend to absorb moisture, as they are mainly composed of cellulose, lignin and hemicelluloses. Hemicelluloses are considered to be primarily responsible for water absorption, although non-crystalline cellulose and lignin also play an important role in this process. The cell walls of the lignocellulosic fiber swell to water saturation. Then, water begins to occupy the free spaces between the fiber bundles and changes their dimensions. ${ }^{16}$ The highest percentage of water sorption reported corresponds to the ULF sample. This may be due to the polar and hydroxyl groups present in natural fibers, capable of forming hydrogen bonds with water. ${ }^{17,18}$

Previous research ${ }^{19}$ has shown that the filler absorbs water by forming hydrogen bonding with water molecules. However, when comparing fiber types, each fiber gives different results and hydrophilicity. For samples LFTP, LFTB, LFTA5 and LFTEJ, it can be observed that the percentage of water absorbed upon saturation decreased, compared to the untreated sample. This may be due to a decrease in hydroxyl groups, leading to a decrease in the hydrophilic characteristic of the fiber. As regards sample LFTS, the silanes grafted to the fiber surface form a network of polysiloxane molecules. Therefore, they modify the morphology of the fibers, causing the Luffa fibers to swell, and they increase the dimensions and porosity of the fibers. The silane treatment also decreases water adsorption by the fibers. ${ }^{20}$

\section{FTIR analysis of Luffa sponge}

Figure 4 presents the FTIR spectra of untreated Luffa sponge (ULF), and treated Luffa sponge. As shown in Figure 4, the broad characteristic peaks near $3338 \mathrm{~cm}^{-1}$ are attributed to the stretching vibrations of hydroxyl $(-\mathrm{OH})$ groups. ${ }^{21,22}$ At $2890 \mathrm{~cm}^{-1}$, the symmetrical and asymmetrical stretching vibration absorption peaks of methyl $\left(-\mathrm{CH}_{3}\right)$ and methylene $\left(-\mathrm{CH}_{2}\right)$ belong to the characteristic cellulose absorption peak. The absorption band observed at 1731.67 $\mathrm{cm}^{-1}$ is related to the stretching of the $\mathrm{C}=\mathrm{O}$ group. This band disappears for the samples treated with alkali, bichromate, permanganate and bleach. This means that hemicelluloses were removed from the fiber surface. ${ }^{23}$

The peak at $1628 \mathrm{~cm}^{-1}$ is attributed to the $\mathrm{O}-\mathrm{H}$ band deformation, due to the hydrophilicity of the Luffa fibers. The peak around $1030 \mathrm{~cm}^{-1}$ is associated with the vibration of the $\mathrm{C}-\mathrm{O}$ bond of hemicelluloses. The peak at $1257 \mathrm{~cm}^{-1}$ corresponds to the vibration of the acetyl group $(\mathrm{C}=\mathrm{O})$ of lignin. The intensity of this peak decreases, which is due to the partial removal of lignin from the fiber surface. ${ }^{24}$ All these results 
NOURI LAIB et al.

support the idea that treatment is essential for the

removal of hemicelluloses and lignin.

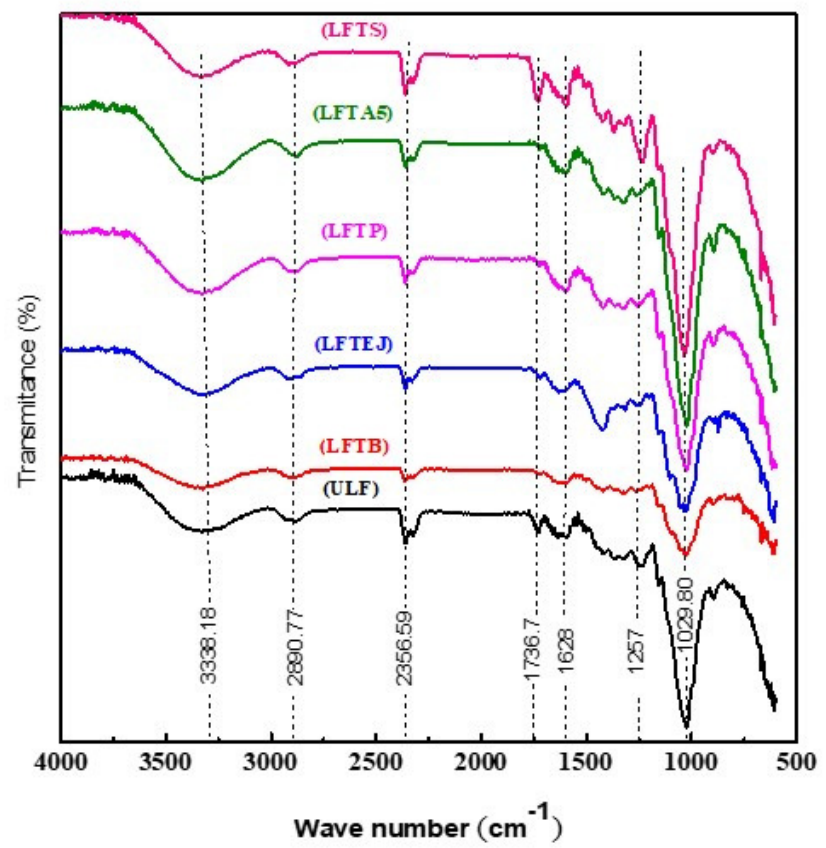

Figure 4: FTIR spectra of treated and untreated Luffa sponge

\section{X-ray diffraction}

Figure 5 shows the X-ray diffractograms of the untreated and treated Luffa sponge. The characteristic peak of the Luffa fiber appears at $2 \theta$ $=15.7$ and 22.8. Table 3 indicates the crystallinity index (CI) obtained by the Segal method. It can be seen that the crystallinity index and the percentage of crystallinity of the Luffa sponge increase after the chemical treatments. The highest crystallinity index is observed for potassium bichromate treated fiber $(70.8 \%)$, followed by permanganate, silane, bleach and

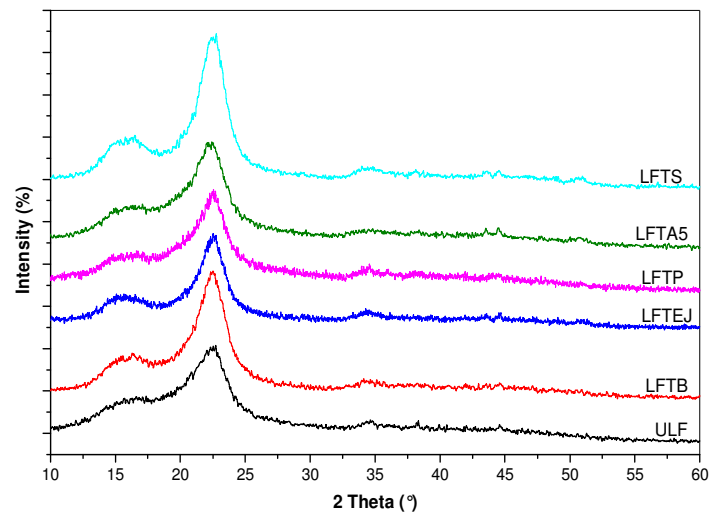

Figure 5: X-ray diffraction patterns of treated and untreated Luffa sponge alkali-treated fibers, respectively. This could be due to better packing and stress relaxation of the cellulose following the removal of amorphous constituents and pectin from the fiber. ${ }^{25,26}$ Benyahia et $a l .{ }^{4}$ reported a similar observation in their work on $\mathrm{NaOH}$ treatment of Alfa fiber. Moreover, the increase in the crystallinity index obtained for samples LFTP, LFTS, LFTEJ and LFTA5 is considered to be the main factor contributing to the improved strength of the Luffa fiber-reinforced composite material.

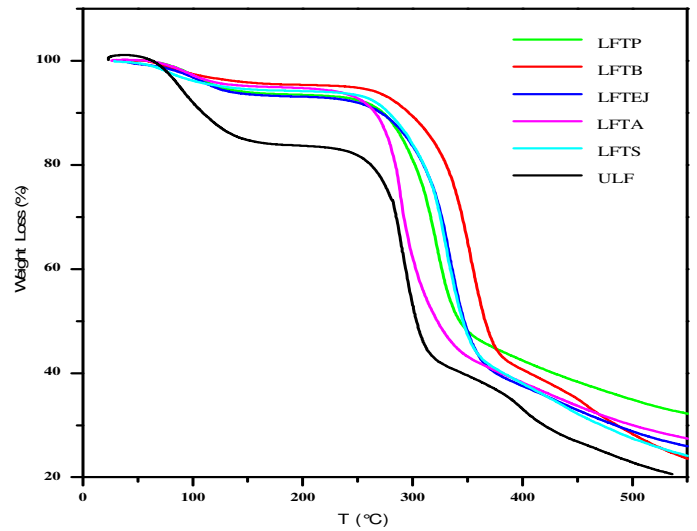

Figure 6: Thermogravimetric curves of treated and untreated Luffa fiber 
Composites

Table 3

Crystallinity index of untreated and treated Luffa sponge

\begin{tabular}{lccc}
\hline Sample & $\mathrm{I}_{002}$ & $\mathrm{I}_{\mathrm{am}}$ & $\mathrm{CI}(\%)$ \\
\hline ULF & 580.88 & 1012.3 & 42.61 \\
LFTA5 & 441.1 & 1100 & 59.9 \\
LFTB & 400 & 1370 & 70.80 \\
LFTP & 375 & 1150 & 67.39 \\
LFTS & 500 & 1630 & 68.48 \\
LFTEJ & 431.5 & 1139.9 & 62.14 \\
\hline
\end{tabular}

\section{Thermogravimetric analysis}

Figure 6 shows the results of the thermogravimetric analysis for raw and treated fiber, respectively. The curves indicate a weight loss at low temperature, which is usually attributed to the loss of water as absorbed moisture or combined water. The weight loss of raw fibers is similar to the values reported for other lignocellulosic fibers, such as jute $(10.2 \%)^{16}$ and flax $(6.3 \%))^{27}$ However, it can be observed that the weight loss of the treated fiber was much lower than that of the raw fiber. This result is an indirect indication that the treatment was effective in reducing the hydrophilic (polar) character of Luffa fibers. It is evident that the thermal stability of chemically treated fibers is higher than that of untreated fibers. The fiber treated with $\mathrm{K}_{2} \mathrm{Cr}_{2} \mathrm{O}_{7}$ shows the best thermal stability. Thus, the first degradation step occurs below $100{ }^{\circ} \mathrm{C}$, with a weight loss of $7.32-9.7 \%$, and it is due to the evaporation of the moisture present in the fibers. ${ }^{28}$

The next step of degradation starts at 264-278 ${ }^{\circ} \mathrm{C}$ and may be due to the degradation of hemicelluloses, the glycosidic bond of cellulose. ${ }^{29}$ The maximum decomposition rate happens at nearly $313{ }^{\circ} \mathrm{C}$ for untreated fibers, but it increases to 337,342 and $360^{\circ} \mathrm{C}$ for the fibers treated with alkali, permanganate, silane, bleach water and $\mathrm{K}_{2} \mathrm{Cr}_{2} \mathrm{O}_{7}$. The thermal decomposition of untreated and alkali-treated fibers is completed at $417{ }^{\circ} \mathrm{C}$. However, it is completed at 429 and $435{ }^{\circ} \mathrm{C}$ for $\mathrm{K}_{2} \mathrm{Cr}_{2} \mathrm{O}_{7}$ treated fibers. Overall, the decomposition of cellulosic substances shifts slightly to higher temperatures for the treated fibers. The increase in thermal stability for the cellulose material may be due to the ordering of the cellulose chains, which leads to greater thermal stability. ${ }^{30}$ However, a study on sisal fiber conducted by V. K. Kaushik et al. ${ }^{31}$ revealed a reduction in thermal stability with alkali treatment (possibly caused by high fibrillation), but an increase with benzoyl peroxide treatment.

\section{Effects of Luffa sponge treatment on flexural strength and modulus of composites}

Figures 7 and 8 present the effect of different chemical treatments on the flexural properties of Luffa sponge/unsaturated polyester composites. It is clearly shown that the different treatments used have a positive impact on the flexural strength, which is higher for the bleach-treated Luffa fiber composite (Fig. 7). The highest reported flexural strength value is $43.2 \mathrm{MPa}$. The flexural modulus also increased for the LFTEJ/UP sample, which shows better flexural properties with a value of $26.04 \mathrm{MPa}$, representing an increase by $37.63 \%$, compared to the untreated Luffa composite (Fig. 8). This was due to the improved bonding between the fiber and the matrix.

\section{SEM analysis}

Figure 9 shows the cross-section of the fracture surface of the composite specimens. The influence of the different surface treatment methods applied on the mechanical properties can be explained by analyzing the interface of the composites. As can be seen in Figure 9 (a) for the ULF/UP sample, the fiber bundles with obvious agglomerations on the material's cross-section are torn off, and there are tear marks and residual holes, indicating poor compatibility between the untreated Luffa fibers and the unsaturated polyester matrix. 


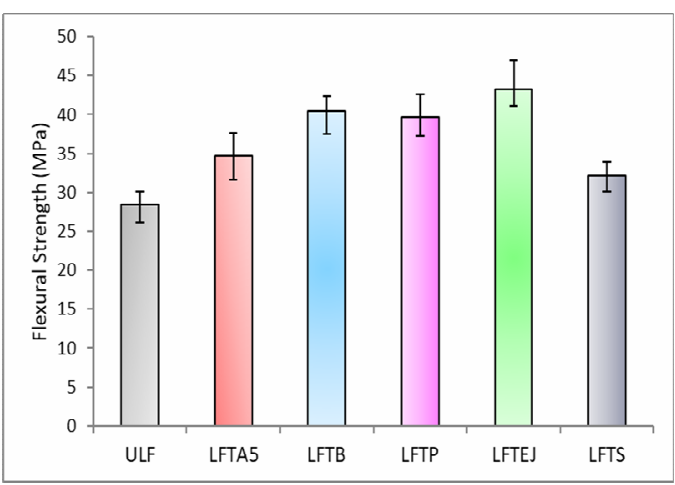

Figure 7: Effect of fiber modification on flexural strength of Luffa fiber-unsaturated polyester composite

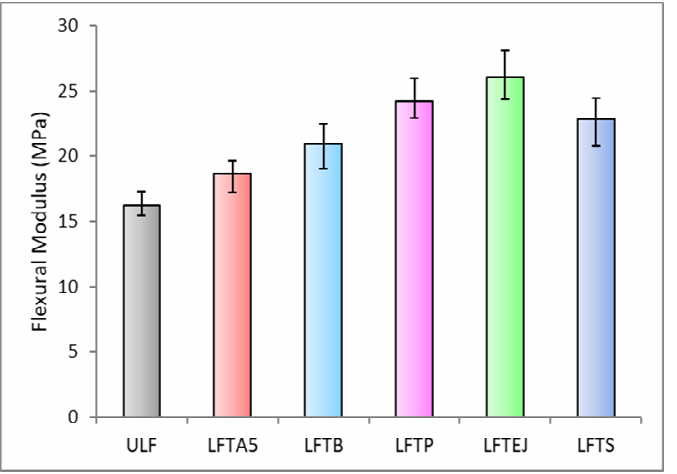

Figure 8: Effect of fiber modification on flexural modulus of Luffa fiber-unsaturated polyester composite
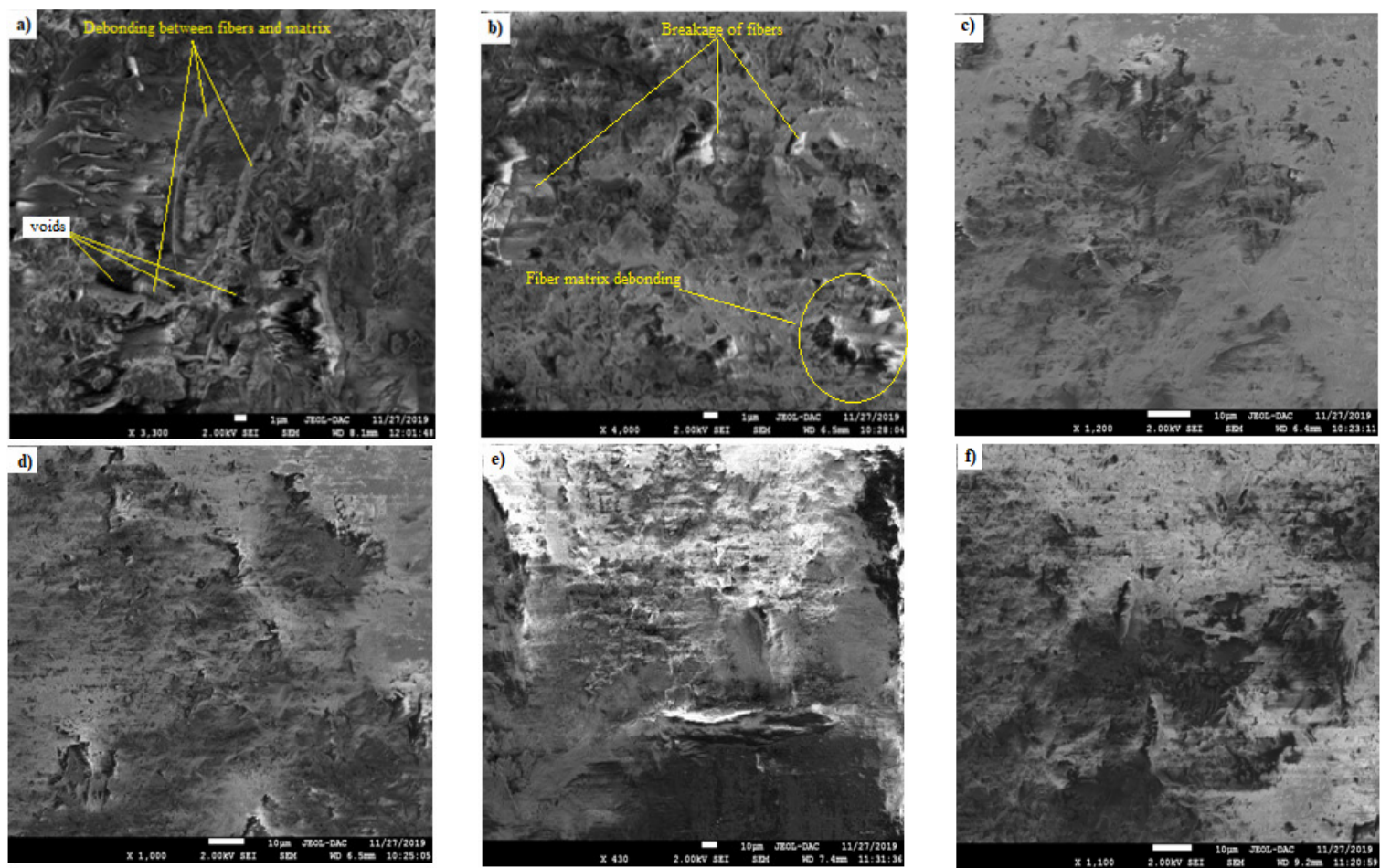

Figure 9: SEM images of fractured surface of composites: a) ULF/UP, b) LFTA5/UP,

c) LFTP/UP, d) LFTEJ/UP, e) LFTB/UP, f) LFTS/UP

The fracture surface of alkali-treated (LFTA5/UP) fiber composites (Fig. 9 (b)) shows fiber breakage rather than tearing, indicating better interfacial strength. ${ }^{32}$ The loss of hemicelluloses and cementitious constituents contributed to the tightening of the cellulose chains, and the fibrils can be reoriented in the tensile direction. ${ }^{33}$ As regards the samples illustrated in Figure 9 (c), (d), (e) and (f), the number of voids is inferior to that of the ULF/UP composite. In addition, there is fibre breakage due to the good adhesion between the fibers and the matrix. This demonstrates an improvement in the mechanical properties of the composites reinforced with treated Luffa fibers.

\section{CONCLUSION}

This study aimed to examine the effects of chemical treatments of Luffa fibers on the mechanical properties of Luffa fiber/unsaturated polyester composites. To this end, several experiments were carried out. The results showed 
that the performance of Luffa fiber reinforced composites is strongly influenced by the surface properties of the fibers. The alkali, permanganate, dichromate, bleach and silane treatments improved the mechanical, i.e. the flexural properties of the composites, compared to the untreated fiber composite, due to the improved interfacial bonding. The results indicated that the maximum improvement in flexural strength, of about $23.80 \%$, was achieved for the bleach treated fiber reinforced composite (LFTEJ/UP) (due to improved interfacial bonding of the fiber with the polyester resin). Thus, based on the satisfying results obtained, it can be concluded that treated Luffa fiber has a very promising potential to be applied in the field of composite materials.

\section{REFERENCES}

1 O. C. Zaske, in "Handbook of Thermoset Plastics", edited by S. H. Goodman, USA, Noyes Publications, 1986, p. 59

2 C. Parida, S. K. Dash and S. C. Das, Ind. J. Mater. Sci., 2015, ID 658064 (2015), http://dx.doi.org/10.1155/2015/658064

3 C. P. Vale, "Glass Reinforced Plastics", London, IL1FFE, 1961, p. 19

4 A. Benyahia, A. Redjem, Z. E. A. Rahmouni and A. Merrouche, Rom. J. Mater., 46, 25 (2016), http://solacolu.chim.upb.ro/p25-33.pdf

5 O. M. L. Asumani, R. G. Reid and R. Paskaramoorthy, Compos. A Appl. Sci. Manuf., 43, 1431 (2012), https://doi.org /10.1016/j.compositesa. 2012.04.007

6 M. S. Islam, S. Hamdan, M. Hasan, A. S. Ahmed and M. R. Rahman, Int. Biodeter. Biodegrad., 72, 108 (2012), https://doi.org/10.1016/j.ibiod.2012.05.019

M. S. Islam, S. Hamdan, I. Jusoh, M. R. Rahman and A. S. Ahmed, Mater. Des., 33, 419 (2012), https://doi.org/10.1016/j.matdes.2011.04.044

${ }^{8}$ V. K. Patel and A. Dhanola, Eng. Sci. Technol. Int. J., 19, $\quad 676 \quad$ (2016), https://doi.org/10.1016/j.jestch.2015.10.005

9 V. O. Tanobe, T. H. Flores-Sahagun, S. C. Amico, G. I. Muniz and K. G. Satyanarayana, Defence Sci. J., 64, 273 (2014), https://doi.org/10.14429/dsj.64.7327

10 A. Dhanola, A. S. Bisht and A. A. Kumar, Mater. Today: Proc., 5, $17021 \quad$ (2018), https://doi.org/10.1016/j.matpr.2018.04.107

11 C. A. Boynard, S. N. Monteiro and J. R. M. D’Almeida, J. Appl. Polym. Sci., 87, 1927 (2003), https://doi.org/10.1002/app.11522

12 M. J. John, B. Francis, K. T. Varghese and S. Thomas, Compos. Part A, 39, 352 (2008), https://doi.org/10.1016/j.compositesa.2007.10.002

13 L. Segal, J. J. Creely, A. E. Martin and C. M. Conrad, Text. Res. J., 29, 786 (1959), https://doi.org/10.1177/004051755902901003
14 M. Nóbrega, L. Carvalho and V. Fonseca, Procs. International Conference on Science and Technology for Sustainable Development, New Delhi, 2006, p. 1

15 P. Gomes de Paula, R. J. S. Rodríguez and L. P. Rangel Duarte, Mater. Sci. Forum, 775, 319 (2014), https://doi.org/10.4028/www.scientific.net/MSF.775776.319

16 S. Das, A. K. Sahan, P. K. Choudhury, R. K. Basak, B. C. Mitra et al., J. Appl. Polym. Sci., 76, 1652 (2000), 4628(20000613)

17 H. Azman, A. S. Arshad, N. A. Farid and A. B. Aznizam, Polym. Compos., 31, 2079 (2010), https://doi.org/10.1002/pc.21006

18 Y. A. Al-Maharma and N. Al-Huniti, J. Compos. Sci., 3, 27 (2019), https://doi.org/10.3390/jcs3010027

19 L. S. Kuburi, D. O. Dauda, S. Umaru, D. DodooArhin, M. B. Balogun et al., Proced. Manuf., 7, 138 (2017), http://ugspace.ug.edu.gh/handle/123456789/27391

${ }^{20}$ K. Bilba and M. A. Arsene, Compos. Part A, 39, 1488 (2008),

https://doi.org/10.1016/j.compositesa.2008.05.013

$21 \mathrm{Q}$. Li and S. Renneckar, Biomacromolecules, 12, 650 (2011), https://doi.org/10.1021/bm101315y

22 A. Khan, R. A. Khan, S. Salmieri, C. L. Tien, B. Riedl et al., Carbohyd. Polym., 90, 1601 (2012), https://doi.org/10.1016/j.carbpol.2012.07.037

23 B. Meghlaoui, M. Ould Ouali and S. Hocine, U.P.B. Sci. Bull., Series B, 81 (2019)

24 A. Benyahia, A. Merrouche, Z. E. A. Rahmouni, M. Rokbi, W. Serge et al., Mechan. Ind., 15, 69 (2014), https://doi.org/10.1051/meca/2013082

25 S. Ouajai and R. A. Shanks, Polym. Degrad. Stabil., $\quad \mathbf{8 9}, \quad 327 \quad$ (2005), https://doi.org/10.1016/j.polymdegradstab.2005.01.016 26 V. Tserki, P. Matzinos, S. Kokkou and C. Panayiotou, Compos. Part A, 36, 965 (2005), https://doi.org/10.1016/j.compositesa.2004.11.010

27 P. R. Hornsby, E. Hinrichsen and K. Tarverdi, J. Mater. Sci., 32, 443 (1997), https://doi.org/10.1023/A:1018521920738

28 K. M. Nair, S. Thomas and G. Groeninck, Compos. Sci. Technol., 61, $2519 \quad$ (2001), https://doi.org/10.1016/S0266-3538(01)00170-1

${ }_{29}$ T. Nguyen, E. Zavarin and E. M. Barrall, J. Macromol. Sci.- Rev. Macromol. Chem., 20, 1 (2007), https://doi.org/10.1080/00222358108080014

30 S. Wong, R. Shanks and A. Hodzic, Compos. Sci. Technol., 64, $1321 \quad$ (2004), https://doi.org/10.1016/j.compscitech.2003.10.012

31 V. K. Kaushik, A. Kumar and S. Kalia, Int. J. Text. Sci., $\quad \mathbf{1}, \quad 101 \quad$ (2012), https://doi.org/10.5923/j.textile.20120106.07

32 K. C. Manikandan, S. M. Diwan and S. Thomas, $J$. Appl. Polym. Sci., 60, $83 \quad$ (1996), https://doi.org/10.1002/(SICI)1097-4628

33 D. Ray and B. K. Sarkar, J. Appl. Polym. Sci., 80, 13 (2001), https://doi.org/10.1002/app.1184 